\title{
Origem do universo, diversidade das espécies e fenômenos da natureza: ciência e religião no ensino médio
}

Eliane Brigida Morais Falcao

Eliane Dias Trigo

\begin{abstract}
Resumo
Investigamos, entre estudantes, as influências que a presença de crenças religiosas exerciam na aprendizagem de conceitos científicos relacionados aos temas "Origem do Universo", "Origem e diversidade da vida" e "Causas dos fenômenos naturais". Foram usados questionário e observação de campo como instrumentos de coleta de dados. Os dados foram analisados à luz da metodologia qualiquantitativa do Discurso do Sujeito Coletivo. A influência de crenças religiosas na dinâmica da aceitação e rejeição das explicações científicas revelou-se claramente. Fez-se notório o esforço de estudantes para harmonizar, a partir de sua base cultural, explicações religiosas e científicas, mas foi possível identificar o aumento de adesão às explicações científicas ao final do ensino médio. Dificuldades dos estudantes não puderam ser atribuídas exclusivamente às influências de crenças religiosas, porque outros fatores foram detectados, como limitado tempo dedicado aos temas investigados e erros em explicações científicas de estudantes que tinham ou não crenças religiosas.
\end{abstract}

Palavras chave: ciência e religião; ensino de biologia; diversidade das espécies; teoria da evolução; ensino médio.

\begin{abstract}
Origin of universe, diversity of species and natural phenomena: science and religion in high school.

It was researched, among students, the influence that the religious beliefs exerted over the learning of scientific concepts related to the themes: "Origin of the Universe", "Origin and diversity of Life", "Causes of Natural Phenomena". Questionnaires and field observation were used as instruments for collecting data, which was analyzed through the Discourse of the Collective Subject methodology of qualitative-quantitative analysis. The influence of religious beliefs in the dynamics of acceptance and rejection of the scientific explanations was revealed. The students' effort to harmonize religious and scientific explanations was noteworthy, but a rise in the adherence to the scientific explanations by the end of high school was identified. Students' difficulties could not be exclusively attributed to the influence of religious beliefs, as other factors, such as the insufficient time dedicated to the themes which were being investigated and inaccuracies in scientific explanations which were identified among students.
\end{abstract}

Keywords: science and religion; biology teaching; diversity of species; theory of evolution; high school. 


\section{Introdução}

O ensino de ciências e suas relações com contextos socioculturais têm sido objetos crescentes de pesquisa nos últimos anos. Gil-Pérez, Vilches e Edwards (2000), por exemplo, investigaram o conhecimento de professores quanto à situação geral do mundo e concluíram pela necessidade de investimento neste aspecto para uma formação mais completa, levando em conta a importância de uma visão mais ampla do mundo na condução dos processos de formação científica.

Autores têm abordado, sob diferentes óticas, aspectos relativos às concepções prévias dos estudantes. Entretanto muitas são as nuances desse repertório a serem mais exploradas, percebidas ou reconhecidas. Dentre essas nuances, estão as relativas às crenças religiosas. Autores como Cobern (1996) e Reiss (2009) já argumentaram no sentido de que os estudantes podem aprender os conceitos científicos sem abrir mão de suas visões de mundo que, muitas vezes, incluem conteúdos não necessariamente restritos aos científicos. Trata-se de um posicionamento que considera a teoria construtivista da educação: a ciência não é a única componente das visões de mundo e sim mais uma, assim como a religião e o senso comum.

Vários trabalhos que analisam concepções prévias dos alunos apontam a influência das crenças religiosas na aceitação das ideias evolucionistas a ponto de, ao final do ensino médio, alunos mesclarem o conceito de evolução a ideias religiosas (CASTRO; AUGUSTO, 2009; COSTA et al, 2011). O Brasil não possui uma tradição criacionista, mas pesquisas já relatam um crescimento do criacionismo no Brasil, que parece muito associado ao surgimento de igrejas evangélicas. 0 proselitismo de algumas dessas igrejas tem trabalhado com a produção e divulgação de materiais educativos como vídeos e livros onde a crítica à teoria da evolução biológica é claramente exposta (SOUZA et al, 2009; SEPULVEDA, 2004). E este parece ser um problema comum a diferentes sociedades do mundo ocidental conforme apontado por Grimoult (2012) que alertou para o papel chave das escolas no sentido de melhor ensinar as normas e os limites das ciências e das religiões.

A teoria da evolução, por outro lado, é pouco compreendida entre os estudantes, no âmbito da educação formal brasileira (ALMEIDA, 2012). Os alunos parecem não utilizar conceitos importantes desta teoria quando vão explicá-la. "Seleção natural" é percebida como abstrata, enquanto reluta-se em aceitar o conceito de "acaso" (ANDERSON et al, 2002, ABRANTES \& ALMEIDA, 2006;). "Evolução"," adaptação" e "competição" possuem sentidos diversos, podendo dificultar a compreensão das ideias científicas que levam os mesmos nomes (BIZZO, 1994; TIDON, LEWONTIN, 2004).

Embora guarde papel de relevante no processo pedagógico escolar, o professor não deve ser olhado como o "vilão" das falhas na aprendizagem. Analisando-se conteúdo programático de biologia previsto para o ensino médio, tomando como base o tempo disponível, no ano letivo e a relevância dos assuntos nele contidos para uma formação científica básica, encontramos alguns 
dos motivos causadores de frustração na ação pedagógica. Embora considerada paradigmática em biologia (MAYR, 1998), evolução tem passagem rápida pelo ensino médio (TIDON, VIEIRA, 2009), sempre em momentos pontuais, de forma descontextualizada (MELLO, 2008), dentro de uma orientação mais descritiva das ciências biológicas. Há um excesso de conteúdos programáticos na grade curricular do ensino médio (CHASSOT, 1998) e o currículo não observa diferenças socioeconômicas dos alunos, desconsiderando os saberes que os estudantes trazem para a sala de aula (OLIVEIRA, 2000). Conhecimento e currículo não são escolhas individuais, mas sim produtos de relações sociais, econômicas, políticas, em última análise, históricas (LOPES, 1998, MOREIRA, 2001). Reformas de ensino, em geral nem sempre correspondem ao que determinada coletividade necessita e não envolvem os professores como agentes dessas mudanças, tornando-os descrentes de tais propostas. Falta valorização dos educadores, em especial dos professores, na definição das políticas publicas de educação aí incluídas as propostas curriculares (CHIZZOTTI, PONCE, 2012).

A pesquisa, aqui relatada, abordou o encontro cultural entre explicações científicas oferecidas na escola e as crenças religiosas de estudantes do ensino médio em um colégio público da rede federal de ensino no Rio de Janeiro. Para isso, foram pesquisadas as possíveis influências que a presença de crenças religiosas exerciam na aprendizagem de conceitos científicos relacionados aos temas "Origem do Universo", "Origem e diversidade da vida" e "Causas de fenômenos naturais".

\section{Objetivos e metodologia}

O presente relato pretende se somar aos que buscam melhor entender as questões que envolvem ensino de ciências e cultura religiosa dos estudantes, ao longo do ensino médio. Considerando que seria muito provável, dado o perfil da cultura brasileira, a presença de crenças religiosas entre os estudantes, decidimos investigar se haveria mudanças entre a primeira e a terceira séries do ensino médio, no contexto de uma boa formação científica básica: haveria um crescimento de adesão às explicações científicas sobre os fenômenos evolutivos? Haveria padrões identificáveis na dinâmica de compreensão e receptividade dos conceitos científicos sobre temas que competem com explicações religiosas? Seria possível detectar e caracterizar a influência de crenças religiosas em tal dinâmica?

A partir dessas indagações, realizamos uma pesquisa comparativa entre a primeira e terceira séries do ensino médio de uma escola federal de reconhecida qualidade no Rio de Janeiro, não só pelas características pedagógicas da instituição como pela constante aprovação de seus alunos em seleções às universidades públicas. Escolhemos alunos de primeira e terceira séries do ensino médio por serem tais níveis de ensino aqueles que correspondem ao início e à 
finalização de estudos sobre conceitos de biologia, considerando-se uma perspectiva de formação científica básica.

Os resultados poderiam fornecer relevantes dados para o aprimoramento das atividades educativas, tanto no que diz respeito ao ensino da teoria evolutiva como também, de uma forma mais geral, para um melhor encaminhamento de temas que provocam o encontro de explicações religiosas e científicas.

O colégio pesquisado é um estabelecimento público conceituado e com baixos índices de evasão. Trata-se de instituição que abriga carreira docente e estimula o aperfeiçoamento profissional de seus professores, por isso, boa parte do grupo docente tem títulos de pós graduação (especialização, mestrado, doutorado). A formação escolar básica nessa instituição vai do primeiro ano do ensino fundamental até a terceira série do ensino médio. $O$ ensino de ciências ou biologia está presente ao longo do curso, sendo o primeiro voltado ao ensino fundamental e o segundo ao ensino médio. O colégio trabalha com coordenações específicas para as diferentes áreas de conhecimento e conta com biblioteca ampla, equipada com livros de literatura, sobretudo brasileira, livros didáticos e paradidáticos atualizados, periódicos e revistas de divulgação de várias áreas do conhecimento. Há microcomputadores com acesso à internet, além daqueles que os alunos também podem acessar localizados nos dois laboratórios de informática. Há dois pequenos laboratórios de ciências, um para química e física e o outro para ciências e biologia. Este segundo conta com um microscópio que pode ser acoplado à televisão, mas o espaço físico é inadequado a uma turma inteira, que possui, em média, de trinta a trinta e cinco alunos. Também não é satisfatoriamente equipado com vidrarias e outros itens necessários a um laboratório escolar. As semelhanças presentes na formação cientifica básica e o fato de formarem um grupo com aspectos socioculturais similares permitiram estabelecer uma comparação, em um estudo transversal, entre os resultados encontrados na primeira série e os obtidos junto à terceira (BLALOCK, 1979). A metodologia qualiquantitativa orientou a coleta de dados mediante aplicação de questionário individual, anônimo. Trabalhou-se com o conceito de representações sociais de Moscovici (2003) e a abordagem de Análise do Discurso do Sujeito Coletivo (LEFÈVRE \& LEFÈVRE, 2003).

O instrumento de coleta de dados foi um questionário que continha perguntas semiabertas sobre o que pretendíamos focar. Elaboramos as questões relativas aos temas "origem do universo" e "origem dos seres vivos" a partir da constatação, mencionada por professores, de que parte dos alunos se referia tanto aos sete dias da criação em contraponto às explicações de base científica da origem do universo quanto à participação divina na origem da espécie humana.

Por isso, para o levantamento das explicações dos alunos para os temas objetos da pesquisa elaboramos as perguntas: Você acredita que Deus fez o mundo em sete dias? Que explicação você daria para o aparecimento dos seres vivos na Terra? Como você explica certos fenômenos da natureza como eclipses, movimentos dos astros, terremotos, tempestades, 
etc.?"Com essas questões, buscamos provocar, de forma clara e objetiva, a expressão das conviç̧ões de cada estudante.

Tendo em vista os objetivos da pesquisa, julgamos necessário investigar o perfil das crenças religiosas de ambos os grupos. Para que se tornasse mais precisa a classificação do aluno como pertencente, ou não, a determinada religião, pedimos que, além de indicá-la no questionário, ele também respondesse se frequentava os cultos religiosos e se acreditava nos preceitos básicos relativos a seu credo religioso (havia perguntas, no questionário, relativas a esses tópicos). Se houvesse incoerência nas respostas do aluno quanto a esse conjunto de quesitos, ele era considerado não pertencente à religião institucionalizada, mas apenas crente em Deus.

As respostas dos alunos a cada uma das questões propostas foram caracterizadas como representações sociais na linha conceitual de Moscovici (op. cit.) Os temas origem da vida e evolução biológica estão envolvidos em explicações científicas e religiosas. E esse conjunto de explicações articula-se a visões de mundo pautadas por ideias, imagens e valores tanto estruturados quanto enraizados nas culturas dos diferentes grupos sociais. Para Moscovici, quando falamos, explicamos ou representamos uma coisa ou uma noção, não relatamos ou produzimos unicamente nossas próprias ideias ou convicções, mas criamos e transmitimos um produto progressivamente elaborado em inúmeros lugares, segundo regras variadas. Os conteúdos expressados, afirma Moscovici, referem-se ao conjunto de conceitos, proposições e explicações originadas no curso de comunicações interpessoais, caracterizadas por influências recíprocas e negociações implícitas. Nesse processo, os indivíduos adquirem um repertório comum de interpretações e explicações, regras e procedimentos que guardam estreitos vínculos com os contextos sociais onde são produzidas. Estudar conteúdos, explicações ou convicções de um determinado grupo em relação a um tema exige, portanto, a compreensão da situação em que são produzidos e comunicados.

Como objetivávamos analisar qualiquantitativamente respostas discursivas (relatos ou depoimentos a respeito de um tema, evento, assunto ou objeto) que são possíveis de identificação com o referencial teórico das representações sociais, optamos pela metodologia de Análise do Discurso do Sujeito Coletivo proposta por Lefèvre \& Lefèvre (op. cit.).

A metodologia do Discurso do Sujeito Coletivo consiste em organizar os relatos dos sujeitos da pesquisa no que Lefèvre e Lefèvre (op.cit.) chamam de figuras metodológicas - ancoragem, ideia central, expressões-chave e discurso do sujeito coletivo. Ancoragem é uma possível qualidade de uma resposta, ou conjunto de respostas, que revela, de maneira marcante, a base inspiradora de aspectos de tal resposta, convicção ou explanação. A ideia central - elaborada pelo pesquisador a partir das expressões-chave dos respondentes - é a essência do que foi expresso na resposta ou relato do sujeito respondente. As expressões-chave são trechos dos relatos que tornam reconhecível sua ideia central, ou seja, seu conteúdo essencial. Um relato pode estar composto de mais de uma ideia central, dando base para diferentes discursos. Ou seja, cada ideia 
central tem seu conjunto de expressões-chave semelhantes, oriundas de diferentes respostas, que permitirão a construção de um discurso do sujeito coletivo.

Cada discurso do sujeito coletivo nasce a partir da junção coerente das expressões-chave colhidas nas respostas reunidas em torno de uma determinada ideia central. O conjunto dos discursos do sujeito coletivo, emitido a respeito do tema ou objeto investigado, expressa a representação social do grupo de indivíduos investigados a respeito daquele tema. Como dizem os autores, o Discurso do Sujeito Coletivo é como se o discurso de todos fosse o discurso de um. 0 conjunto dos discursos do sujeito coletivo de um grupo reflete as diferentes faces discursivas de um grupo social sobre o tema investigado, ou seja, a representação social do grupo em relação ao tema investigado. Cada grupo de alunos (primeira e terceira séries) foi analisado separadamente e a seguir foi feita a análise comparativa. A comparação se deu em termos das quantidades de alunos por tipo de resposta para cada pergunta e também em relação ao teor da resposta dada. Desse modo, pudemos ter ideia do que permanecia e do que se modificava em torno dos temas pesquisados no tocante à visão religiosa e à científica dos alunos.

\section{Resultados da pesquisa}

Os resultados mostraram que os estudantes da primeira e terceira séries possuíam perfis socioculturais semelhantes. A maioria dos alunos da primeira série tinha 15 anos, enquanto a maior parte da terceira estava com 17 anos. A maioria dos participantes da pesquisa estudavam juntos desde o primeiro ano, sexto ou sétimo ano do ensino fundamental, ou seja, esses alunos estavam juntos desde os primeiros anos da vida escolar, de forma que quase todos tiveram acesso à mesma formação e viveram no mesmo ambiente escolar por vários anos.

Professores de biologia do colégio foram contatados a respeito do ensino dos temas em foco e alegaram que, frente à quantidade e complexidade de tópicos do programa do ensino, não havia tempo para o desenvolvimento satisfatório dos mesmos. Tais relatos se juntam aos de outros grupos, conforme nos mostraram as pesquisas de Mello (2008) e Tidon, Vieira (2009) citadas anteriormente e que destacaram a passagem rápida, pontual e descontextualizada da teoria da evolução no currículo de biologia do ensino médio, currículo este prioritariamente descritivo, informativo e extenso (Chassot, 1998).

Quanto à escolaridade dos pais dos estudantes, nos dois grupos pesquisados, mais de $40 \%$ completaram o ensino universitário. Em relação à crença em Deus, mais de $80 \%$ dos estudantes, tanto na primeira quanto na terceira séries, disseram acreditar em Deus. Em ambos os grupos, as percentagens de alunos que duvidavam da existência de Deus, embora baixas em relação aos que acreditavam, duplicaram na terceira série. Quanto ao número de alunos ateus, o percentual não chegou a 3\% nas duas séries. A Tabela 1 sumariza esses dados. 
Tabela 1.- Padrão de Crença em Deus.

\begin{tabular}{|c|c|c|}
\hline $\begin{array}{c}\text { Padrão de crença em } \\
\text { Deus }\end{array}$ & 1a Série & 3a Série \\
\hline Tem religião & $71(66,4 \%)$ & $54(51,9 \%)$ \\
\hline Crença em Deus sem & $27(25,2 \%)$ & $31(29,8 \%)$ \\
\hline religião & $6(5,6 \%)$ & $16(15,4 \%)$ \\
\hline Deus Dúvida da existência de $\quad$ & $3(2,8 \%)$ & $3(2,9 \%)$ \\
\hline
\end{tabular}

Tendo em vista que mais de $80 \%$ dos alunos (cerca de $90 \%$ na primeira série e cerca de $80 \%$ na terceira série) acreditam em Deus, fora ou dentro do contexto de uma religião, podemos afirmar que as crenças religiosas estão presentes na bagagem cultural desses estudantes.

O termo cultura, neste artigo, é usado na linha conceitual de Geertz (1989): cultura é a produção de significações elaboradas por um determinado grupo e que se traduz por formas de pensar, agir e sentir profundamente incorporadas pelo grupo, de tal sorte que, ainda que produzidas coletivamente e através de longos períodos de tempo, são percebidas ou aceitas como produções próprias. Nota-se que nas religiões católica, evangélica e espírita concentrou-se maior número de estudantes; as outras denominações, como a Tabela 2 mostra, apresentaram número de adeptos muito reduzido.

Esses dados mostram que pelo menos a metade dos estudantes, tanto da primeira quanto da terceira séries, pertence a religiões institucionalizadas. Na terceira série, aparece uma queda do percentual desse padrão, o que leva a crescer o número dos que creem em Deus sem aderir à religião e dos que duvidam da existência de Deus, sendo estes em menor número, que representa, porém, um percentual bem mais expressivo daquele que aparece na primeira série. Dentre as religiões, a católica é predominante nos dois grupos.

A Tabela 2 mostra o perfil das opções religiosas mencionadas nas respostas dos alunos. 
Tabela 2- Religiões, Crença em Deus, Ateísmo.

\begin{tabular}{|c|c|c|}
\hline \multicolumn{1}{|c|}{ Religião } & 1a. Série & 3a. Série \\
\hline Católica & $43(40,2 \%)$ & $26(25 \%)$ \\
\hline Espírita & $9(8,4 \%)$ & $10(9,6 \%)$ \\
\hline Evangélica & $11(10,3 \%)$ & $9(8,6 \%)$ \\
\hline Judaica & $1(0,9 \%)$ & -- \\
\hline Messiânica & -- & $3(2,9 \%)$ \\
\hline Mórmon & $1(0,9 \%)$ & -- \\
\hline Seicho-no-ie & $1(0,9 \%)$ & $3(2,9 \%)$ \\
\hline Umbanda & $3(2,8 \%)$ & $2(2 \%)$ \\
\hline Wicca & $2(1,9 \%)$ & $47(45,1 \%)$ \\
\hline Crença em Deus (sem & $33(30,9 \%)$ & $3(2,9 \%)$ \\
\hline religião) & $3(2,8 \%)$ & \\
\hline Ateu & & \\
\hline
\end{tabular}

As representações sociais dos estudantes relativas aos três temas investigados - origem do universo, origem dos seres vivos e causas dos fenômenos da natureza - apresentaram alguns aspectos comuns. Em ambos os grupos, em relação aos temas estudados, constatamos um conjunto de pensamentos valores e imagens que deram origem às mesmas ideias centrais, eixo de cada um dos discursos coletivos (doravante o termo "discurso coletivo" será referido simplesmente como "discurso"). A diferença constatada entre os dois grupos refere-se à menor ou maior adesão aos diferentes discursos na passagem da primeira para a terceira série.

As ancoragens dos discursos foram as crenças religiosas de origem cristã e as explicações de base científica oferecidas na escola. Assim, em ambos os grupos, apareceram bem caracterizados o discurso religioso e o discurso escolar de base científica, que, associados, deram surgimento a um terceiro discurso que mostrou o esforço dos sujeitos de compatibilizar um e outro conjunto de explicações. Dois outros discursos, de menor adesão por parte dos alunos, foram também levantados: um expressou dúvidas e outro declarou ignorância diante do assunto.

Conforme já mencionamos, a Tabela 1 mostra a diminuição do número de estudantes da terceira série que se declararam adeptos de uma religião. A análise desse resultado permitiu-nos a verificação de que a religião que sofreu maior perda foi a católica. O percentual dos estudantes evangélicos e espíritas permaneceu, praticamente, o mesmo nos dois grupos. A seguir,

DOI: Em andamento. 
apresentamos os discursos da representação social para os temas investigados. Os discursos foram editados (apenas cortes de expressões ou termos semelhantes) mantendo-se a integridade discursiva dos grupos investigados.

Para a pergunta "Você acredita que Deus fez o mundo em sete dias?" foram identificadas cinco ideias centrais, que geraram cinco discursos diferentes, tanto na primeira série quanto na terceira: Deus criou o mundo em sete dias; Deus não criou o mundo; Deus criou o mundo e a vida evoluiu; Fico em dúvida entre o que diz a ciência e a religião; Não sei como o mundo foi criado.

A seguir, a Tabela 3 sumariza o percentual de adesão dos estudantes a cada um desses discursos.

Tabela 3 - Distribuição dos discursos sobre a origem do universo.

\begin{tabular}{|c|c|c|}
\hline Discursos do Sujeito Coletivo & $\begin{array}{r}\mathbf{1}^{\text {a }} \text { série } \\
\mathbf{n}=\mathbf{1 0 4}\end{array}$ & $\begin{array}{r}\mathbf{3}^{\mathbf{a}} \text { série } \\
\mathbf{n = 1 0 5}\end{array}$ \\
\hline 1. Deus criou o mundo em sete dias & $\begin{array}{c}38 \\
(35,5 \%)\end{array}$ & $\begin{array}{c}17 \\
(16,2 \%)\end{array}$ \\
\hline 2. Deus não criou o mundo & 24 & 38 \\
& $(22,4 \%)$ & $(36,2 \%)$ \\
\hline 3. Deus criou o mundo e a vida evoluiu & 20 & 32 \\
\hline 4. Fico em dúvida entre o que diz a ciência & $(18,7 \%)$ & $(30,4 \%)$ \\
\hline e a religião & $(12,2 \%)$ & $9(8,6 \%)$ \\
\hline 5. Não sei como o mundo foi criado & $9(8,4 \%)$ & $9(8,6 \%)$ \\
\hline Não responderam & $3(2,8 \%)$ & -- \\
\hline
\end{tabular}

(*) Um aluno da 3a série teve sua resposta desmembrada em duas ideias centrais diferentes, razão para se considerar, para efeito estatístico, haver 105 alunos nesta série e não 104, como, de fato, ocorre.

O discurso "Deus criou o mundo em sete dias" foi o que apresentou percentual de queda mais expressiva quando se comparam as duas séries. Ele nos remete a conviç̧ões religiosas de parte dos sujeitos pesquisados no que se refere ao tema da origem do universo, como podemos perceber nos seguintes discursos:

"Conforme diz a Bíblia, Deus fez o mundo em seis dias e no sétimo descansou. Acredito na Bíblia, pois ela foi escrita pelos apóstolos e por Jesus". (Discurso 1 - Origem do universo, 1a série).

E também no discurso dos estudantes da terceira série: 
"Deus fez o mundo em sete dias, ou melhor, fez o mundo em seis dias e no 70 dia descansou, entregando-o aos homens (...) A Bíblia conta toda a criação do mundo no primeiro livro, o Gênesis". (Discurso 1 - Origem do universo, 3a série).

Constatamos que, entre uma série e outra, a maior estabilidade dessa crença ocorreu entre os evangélicos; já entre os católicos houve afastamento dessa convicção na terceira série.

O discurso "Deus não criou o mundo", entre uma série e outra, teve seu percentual de adeptos bastante aumentado, o que revela a influência exercida pelo conhecimento científico ao longo do curso médio. Nos discursos a seguir, notamos também a presença de críticas ao posicionamento da crença religiosa baseada na interpretação literal da Bíblia. Entre os estudantes da primeira série:

"Deus não criou o mundo. Ele não é (...) o Niemeyer. Não há nenhuma pesquisa cientifica que possa me provar tal fato. A própria ciência já contesta este fato". (Discurso 2 - Origem do universo, $1 \stackrel{a}{a}$ série).

E entre os estudantes da terceira série:

"Como comprovar que Deus fez o mundo em sete dias? Eu acho que, hoje em dia, a tendência será, cada vez mais, acreditar na ciência, pois ela possui mais provas para fazer as pessoas acreditarem que foi um fato científico" (Discurso 2 - Origem do universo, $3 \stackrel{a}{a}$ série).

Aderiram a esse discurso tanto os alunos ateus de ambas as séries, quanto parte dos que só acreditam em Deus, bem como os que têm religiões como católicas e espíritas.

Quanto ao discurso que procura compatibilizar a crença religiosa e o ensino científico - Deus criou o mundo e a vida evoluiu -, observamos que ele também teve um percentual de crescimento na terceira série. Essa tentativa de harmonizar o conhecimento científico e o religioso está ilustrada nos discursos a seguir.

Entre os estudantes da primeira série:

"Eu acredito que os sete dias de Deus sejam milhões de anos para nós(...). Ele fez a vida e o mundo evoluírem em milhões de anos(...) Deus criou tudo, mas como a ciência descreve." (Discurso 3, Origem do Universo, 1a série).

E entre os estudantes da terceira série:

"O mundo foi criado a partir de elementos físicos, mas também houve a participação de uma força superior. Acredito nas hipóteses científicas sobre o surgimento do mundo, do nosso planeta e dos seres, porém acredito 
plenamente na presença de Deus." (...) (Discurso 3, Origem do universo, $3 \underline{a}$ série).

Esse discurso afirma que Deus deu origem a tudo, mas a ciência explicaria o desenrolar da criação. Chamou nossa atenção a presença, nesse discurso, de um olhar crítico em relação à interpretação literal dos textos bíblicos que acontece especialmente na terceira série. Católicos, espíritas e os que só acreditam em Deus sem aderir a uma religião compartilharam esse discurso tanto na primeira quanto na terceira série.

Consideramos que o quarto discurso - que expressa dúvidas - poderia também ser identificado como o do conflito. Nele, as dúvidas apareceram em relação à ciência e à religião, conforme indicam os discursos:

"A ciência tem uma explicação para a formação do mundo e a religião tem outra. Tenho muitas dúvidas sobre alguns assuntos relacionados à ciência e à religião. Por isso, acredito na explicação da religião, mas também na do Big Bang. Melhor dizendo, fico na dúvida em qual acreditar" (Discurso 4, Origem do universo, $1 \underline{a}$ série).

E também na terceira série:

"Não tenho certeza se Deus fez o mundo (...) Acredito nas teorias cientificas, mas é muito difícil pensar em tudo isso, tendo uma religião". (Discurso 4, Origem do Universo, $3 \underline{a}_{\text {série). }}$.

Observamos que o estudante que expressa esse discurso encontra-se pressionado diante do dilema: Deus criou ou a ciência explica? Essa questão apareceu, tanto na primeira quanto na terceira séries, principalmente entre alunos católicos e aqueles que só acreditam em Deus.

O discurso "Não sei como o mundo foi criado" assemelha-se ao anterior e foi o que mostrou maior estabilidade tanto em relação ao número de seus adeptos quanto ao tipo de argumentação apresentada em ambos os grupos pesquisados. Pode-se perceber o conflito entre as explicações científicas e religiosas conforme sugerem os discursos.

"Não sei como o mundo foi criado. Não posso afirmar se não vi, isso é que dizem! Nunca parei para pensar nisso". (Discurso 5, Origem do Universo, $1 \underline{a}_{\text {série) }}$.

E entre os estudantes da terceira série:

"A criação em sete dias é o que os homens dizem, aí eles colocam as coisas como querem do ponto de vista deles. Isso são histórias não comprovadas e eu não tenho base para responder melhor, pois não li a Bíblia e não lembro nada do que aprendi" (Discurso 5, Origem do universo, 3a série). 
Em resumo, no que se refere ao tema da origem do universo, observamos que a tendência no terceiro ano foi de adesão aos discursos que incluem valorização da explicação científica, mas houve também expressão de evidentes conflitos entre ciência e religião em parte do grupo e notou-se, em relação ao conjunto de religiões presentes, a menor adesão de estudantes evangélicos às explicações da ciência.

Para a pergunta "Que explicação você daria para o aparecimento dos seres vivos na Terra?" foram construídas quatro ideias centrais que geraram quatro diferentes discursos em ambas as séries. As ideias centrais foram: Os seres vivos foram criados por Deus; A origem dos seres vivos é explicada pela ciência; A origem dos seres vivos é explicada por Deus e pela ciência; Não sei explicar. A Tabela 4 permite-nos a visualização quantitativa do percentual de adesão dos estudantes a cada um desses discursos.

Tabela 4.- Distribuição dos discursos sobre as explicações para a origem dos seres vivos na Terra.

\begin{tabular}{|c|c|c|}
\hline Discursos do Sujeito Coletivo & $\begin{array}{r}\mathbf{1}^{\text {a }} \text { série } \\
\mathbf{n = 1 1 1}\end{array}$ & $\begin{array}{r}\mathbf{3}^{\text {a }} \text { série } \\
\mathbf{n = 1 0 4}\end{array}$ \\
\hline 1. Os seres vivos foram criados por Deus & $\begin{array}{c}49 \\
(44,2 \%)\end{array}$ & $(23,1 \%)$ \\
\hline 2. A origem dos seres vivos é explicada pela & 44 & $51(49 \%)$ \\
\hline ciência & $(39,6 \%)$ & 24 \\
\hline 3eus e pela ciência. & 11 & $(23,1 \%)$ \\
\hline 4. Não sei explicar. & $7(6,3 \%)$ & $5(4,8 \%)$ \\
\hline
\end{tabular}

$\left({ }^{*}\right)$ Dois alunos da 1 a série tiveram suas respostas desmembradas em duas ideias centrais diferentes, razão para se considerar, para efeito estatístico, haver 111 alunos nesta série e não 107, como, de fato, ocorre.

A Tabela 4 nos mostra que o discurso 1"Os seres vivos foram criados por Deus" sofreu uma queda no percentual de seus adeptos bastante expressiva na terceira série. Cresceu, no terceiro ano, a adesão às explicações científicas que foram expressas tanto no discurso 2 como no discurso 3.

O que caracteriza o discurso 1 é a afirmação da crença na intervenção divina associada à concepção da ciência como um conjunto de teorias pouco claras que, por estarem em constante processo de atualização, não mereceriam confiança, diferentemente das explicações bíblicas, consideradas mais sólidas. Confiram-se os discursos:

DOI: Em andamento. 
"Deus fez o Universo, a Terra, o céu, o mar, e os seres vivos. Tudo na Terra e fora da terra foi criado por Ele na sua hora e no seu momento" (Discurso 1, Origem dos Seres Vivos, $1 \underline{a}_{\text {série}}$.

E, entre estudantes da 3asérie:

"A justificativa se encontra no primeiro Livro da Bíblia, Gênesis, que diz que a Terra era disforme e Deus foi criando vidas para nela habitar (...) Apesar de toda teoria científica, os seres vivos começaram a aparecer por vontade de Deus. As teorias evolutivas são muito incertas e confusas; a cada momento, a origem da vida é vista de maneira diferente. Não acredito nelas" (Discurso 1, Origem dos seres vivos, 3 a série).

Na primeira série, a maior parte dos alunos evangélicos adotou o discurso 1, mas houve também católicos entre seus adeptos. Na terceira série, ocorreu uma distinção entre esses dois segmentos religiosos: os evangélicos permaneceram com esse discurso enquanto parte significativa dos católicos migrou para o discurso 2 que será tratado a seguir.

Na comparação entre a primeira e a terceira séries, notamos um crescimento em cerca de $10 \%$ do percentual do discurso 2 "A origem dos seres vivos é explicada pela ciência." Confira-se esse discurso entre os estudantes da 1 ạ série:

"A Terra teve todas as qualidades necessárias para se ter vida. (...) microrganismos deram origem a outros, pois todos sabem que os seres vivos descendem do primeiro ser pluricelular que se formou com outros unicelulares. Bactérias se juntaram formando outras. Um germe gerou um animal, que gerou outro tipo. Através da mutação, eles surgiram e depois sobreviveram ou não por seleção natural, até chegar ao macaco e, a partir dele o homem" (Discurso 2, Origem dos seres vivos, $1^{1}$ série).

A maioria dos estudantes da terceira série, (à exceção dos evangélicos) independentemente de ter ou não religião, também optou por tal discurso: ateus, católicos, alunos que só creem em Deus e aqueles que duvidam de sua existência. Nessa série, os argumentos apresentados ofereceram maior clareza e precisão científicas. O discurso da terceira série, a seguir é ilustrativo:

"O aparecimento dos seres vivos faz parte da evolução do planeta. Devido às condições favoráveis ao surgimento da vida, nós fomos evoluindo conforme os milhares de anos foram se passando (...). A junção de aminoácidos na sopa nutritiva gerou (...) coacervados (precursores dos seres vivos). Esses seres primitivos foram, com a ajuda de fatores naturais, sofrendo mudanças genéticas, até atingir a complexidade que temos hoje. Finalmente, através dos primatas (seres mais próximos do homem na escala evolutiva) foi que o homem evoluiu" (Discurso 2, Origem dos seres vivos, 3a série).

124 DOI: Em andamento.

R. Bras. de Ensino de C\&T 
Nota-se que no primeiro ano do ensino médio, os estudantes, nessa escola, já relacionam surgimento da vida com processos de transformação da Terra ao longo do tempo e diversidade dos seres vivos com fenômenos como seleção natural e mutação. Embora esteja presente a perspectiva da ciência, foram encontrados erros conceituais como o que afirma que seres vivos evoluem de forma linear e seqüencial, "juntando-se" uns aos outros, formando outros seres mais complexos e a descendência linear do homem a partir do macaco. No terceiro ano, ainda que esteja sugerida possível associação de grau de complexidade à noção de progresso, um dos equívocos de compreensão dos processos evolutivos, o discurso científico se mostra mais aprimorado, pois revela o entendimento dos estudantes acerca das mudanças do planeta ao longo do tempo como fator que proporcionou as condições necessárias à origem dos seres vivos. Houve uso mais correto de termos técnicos como aminoácidos, coacervados e mudanças genéticas e está expressa a compreensão correta do surgimento da espécie humana a partir de um ancestral comum com o macaco.

Outro dado que chamou nossa atenção, na análise do discurso 2, foi o de que os espíritas o abandonaram na terceira série, migrando, quase todos, para o discurso da compatibilidade entre ciência e religião, ou seja, para o discurso 3 "A origem dos seres vivos é explicada por Deus e pela ciência", nitidamente, por eles, expresso:

"Os seres vivos não surgiram do nada nem por obra do acaso, mas sim por vontade de Deus, mediante as necessidades do mundo, unida à evolução do planeta, gradativamente, num encadeamento lógico e científico. Tem que haver uma razão para toda essa beleza e perfeição que é a natureza, não pode ter surgido do nada (...). Para mim é um acontecimento divino (...) Deus quis criar, e do resto, a natureza se encarregou, pois eu acredito em evolução das espécies" (Discurso 3, Origem dos seres vivos, 3aㅗ série).

O discurso expresso no primeiro ano, embora de menor adesão e com uso de menos termos de ciência foi semelhante:

"A Terra mudou durante os anos, fazendo com que os seres vivos aparecessem evoluídos de aminoácidos. Deus só criou um ambiente para que a vida pudesse acontecer e dar frutos (...). A menor porção surgiu ao acaso e foi evoluindo até chegar aos animais e aos homens. É o que penso por causa da religião e da ciência" (Discurso 3, Origem dos seres vivos, $1^{\underline{a}}$ série)

Esse discurso mostra esforço de associar explicação religiosa e científica para a origem dos seres vivos, tenta integrar o ato da criação divina com a visão científica de um processo gradativo e encadeado. $\mathrm{O}$ que, basicamente, o diferenciou do discurso anterior foi tanto a declaração de crença na intervenção divina como a explícita negação do acaso, um dos conceitos básicos para a compreensão da teoria da origem e diversidade da vida. O número de alunos que partilhou desse 
discurso na terceira série cresceu de forma expressiva, contando, majoritariamente, com católicos e espíritas.

O último discurso "Não sei explicar", de menor adesão, expressa em ambas as series investigadas, tanto uma insatisfação com as explicações da ciência oferecidas pela escola como certa tendência a afirmar o "inexplicável" dos fenômenos da vida.

"Ainda não entendo inúmeras coisas dessa vida e o aparecimento dos seres vivos é uma delas. Se houve vontade de Deus, ou não, eu não sei. São tantas coisas que falam, que não consigo chegar a alguma conclusão. Não sei explicar como surgiram os seres vivos (...) é um fenômeno natural que não pode ou não vai ser explicado" (Discurso 4, Origem dos seres vivos, $1^{\underline{a}}$ série).

"Não acredito que tenha sido Deus o criador, mas também não foi o puro acaso, até porque acaso já dá uma ideia transcendental. Não acredito em nenhuma teoria até hoje criada para justificar o aparecimento dos seres vivos. A energia e as forças do universo (naturais) por algum motivo se modificaram. Mas não sei porque a historia tomou esse curso. Espero que algum dia alguém descubra."( Discurso 4, Origem dos seres vivos 3asérie)

Notamos, nessa argumentação, certa inclinação a se considerar a origem dos seres vivos como um mistério que escapa a qualquer tentativa de compreensão racional. O número de seus adeptos foi semelhante nos dois grupos pesquisados. Quanto às crenças religiosas registradas nesse discurso, na primeira série, apareceram católicos e os que apenas creem em Deus. Na terceira série, adotaram esse discurso apenas estudantes que ou só creem em Deus, sem adesão a religião, ou os que duvidavam da sua existência. Em resumo, como aconteceu na representação relativa à origem do universo, a mudança mais significativa encontrada em relação à origem dos seres vivos foi a que mostrou, entre os estudantes da terceira série, a inclusão mais extensa das explicações científicas em seus discursos e sem que isso significasse exclusão das crenças religiosas pessoais para a maior parte deles. Entre esses alunos, houve também um esforço de compatibilização entre ciência e religião.

Para a pergunta "Como você explica fenômenos da natureza?", identificamos, em cada um dos grupos, três ideias centrais que permitiram a construção de três discursos diferentes tanto na primeira quanto na terceira séries. As ideias centrais foram: "Os fenômenos da natureza foram criados por Deus";" Os fenômenos da natureza não foram criados por Deus"; "Não sei explicar". A Tabela 5 permite a visualização quantitativa do percentual de adesão dos estudantes a cada um desses discursos.

126 DOI: Em andamento. 
Tabela 5 - Distribuição dos discursos sobre as causas dos fenômenos da natureza.

\begin{tabular}{|c|c|c|}
\hline Discursos do Sujeito Coletivo & $\begin{array}{c}1^{\text {a }} \text { série } \\
107\end{array}$ & $\begin{array}{c}3^{\text {a }} \text { série } \\
106\end{array}$ \\
\hline $\begin{array}{c}\text { 1. Os fenômenos da natureza foram criados } \\
\text { por Deus }\end{array}$ & $\begin{array}{c}22 \\
(20,6 \%)\end{array}$ & $\begin{array}{c}25 \\
(23,6 \%)\end{array}$ \\
\hline $\begin{array}{c}\text { 2.Os fenômenos da natureza não foram } \\
\text { criados por Deus }\end{array}$ & $\begin{array}{c}82 \\
(76,6 \%)\end{array}$ \\
\hline 3. Não sei explicar & $3(2,8 \%)$ & $4(3,8 \%)$ \\
\hline
\end{tabular}

(*) Um aluno da 3a série teve sua resposta desmembrada em duas ideias centrais diferentes, razão para se considerar, para efeito estatístico, haver 106 alunos nesta série e não 104.

Dos três temas investigados, este último - explicações para os fenômenos naturais - foi o que obteve resultados quantitativos e qualitativos mais semelhantes na comparação entre a primeira série e a terceira.

No discurso "Os fenômenos da natureza foram criados por Deus", Deus apareceu como o criador e o controlador dos fenômenos naturais. Além disso, aí também se considerou que os fenômenos naturais catastróficos representavam uma punição divina aos seres humanos que "estragam" a natureza. Comparem-se os discursos das duas séries:

"Deus também castiga, tanto quanto como faz as belezas (...) Somos nós que estragamos a terra e a natureza (...) Outras vezes, chegou a hora da pessoa morrer ou então o diabo faz catástrofes para matar" (Discurso 1, Fenômenos da Natureza, $1 \underline{a}_{\text {série). }}$.

"Os fenômenos naturais que, para a maioria dos homens, só têm explicação física, nenhum motivo além, não acontecem sem a permissão ou o controle divino. Deus é a força suprema e nada é simplesmente o acaso (...) após o pecado do homem muitas coisas se distorceram e Deus permitiu isso para equilibrar o planeta".(Discurso 1, Fenômenos da natureza, 3ํㅗ série).

Nesse discurso, concentraram-se, majoritariamente, alunos evangélicos, mas, também, alguns católicos e espíritas.

O discurso 2 da não intervenção divina em fenômenos naturais é o que prevaleceu tanto na primeira quanto na terceira séries. Está ele mais próximo do ponto de vista científico, o que podemos ver pelo vasto emprego de termos e argumentos científicos, conforme atestam os discursos das duas séries investigadas:

R. B. E. C. T., vol 8, núm. 1, jan-abr.2015 ISSN - 1982-873X

DOI: Em andamento. 
"Terremotos ocorrem pela recente formação geológica que ainda procura se firmar (...). Tempestades acontecem pela evaporação da água que condensa e volta como chuva. Eclipses ocorrem quando o Sol é tapado pela Lua. Em resumo, acontecimentos físicos geram os fenômenos naturais. (...) Deus, um ser de amor, bom e que perdoa, não criaria esses fenômenos de propósito (...) fatos naturais e geográficos ocorrem por acaso". (Discurso 2, Fenômenos da

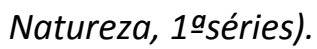

"Foi provado por ciências como biologia, física, química, matemática e geografia que fenômenos naturais ocorrem devido a vários fatores: diversas substâncias que estão em constantes ciclos de transformação (...) direção dos ventos e encontro de massas de ar; localização das placas tectônicas; movimentos na crosta terrestre ou dos corpos celestes; influência do clima e outros fatores naturais. (...) Não é nenhum castigo (...)." (Discurso 2, Fenômenos da natureza, 3asérie).

É interessante notar que esse discurso, diferentemente dos demais relativos à origem do universo e diversidade das espécies, foi partilhado por alunos de todas as crenças religiosas, institucionalizadas ou não - católicos, espíritas, evangélicos (alguns), aqueles que só creem em Deus -, e também por aqueles que duvidavam da existência de Deus ou que eram ateus. À exceção dos evangélicos, todas as outras categorias de crenças religiosas encontravam-se, majoritariamente, nesse discurso.

O discurso "Não sei explicar", que teve percentuais de adesão bastante baixos em ambos os grupos, declara o desconhecimento a respeito das causas para fenômenos naturais. Os discursos seguintes são característicos dessa opção:

"Não tenho certeza, acho que não sei explicar a causa dos fenômenos naturais. Sei lá, acho que isso já é da natureza" (Discurso 3, Fenômenos da natureza, 1aa série);

"Sinceramente, eu não sei explicar a razão dos fenômenos da natureza. Nunca pensei a respeito. Acho que eles devem acontecer a partir da natureza criada, mas reconheço que não tenho informação sobre esse tipo de questão" (Discurso 3, Fenômenos da natureza, 3a série).

Entre seus adeptos, na primeira série, um era ateu, um católico e um evangélico; já na terceira série, dois alunos eram espíritas e dois se disseram crentes em Deus sem aderirem a uma religião. 


\section{Discussão dos resultados}

Os resultados nos indicaram que a maioria dos alunos pesquisados na primeira série pertencia a religiões institucionalizadas cristãs, o que não acontecia na terceira série. Nesta, cresceu o percentual tanto dos alunos que acreditavam em Deus sem aderir a uma religião quanto daqueles que duvidavam da existência de Deus (Tabela 2). É importante ressaltar que o colégio onde a pesquisa foi realizada é público e não tem ensino religioso

Levando em conta os dados da Tabela 2, observamos a queda do número de alunos católicos na terceira série em comparação aos da primeira série. Como os percentuais relativos aos evangélicos e espíritas oscilaram pouco de um grupo para outro, foi-nos possível supor que fossem católicos os que mais abandonaram suas crenças religiosas no período. Isso pode estar relacionado com a pouca doutrinação requerida para a adesão e manutenção da crença católica, comparativamente ao que ocorre com o espiritismo e com as religiões evangélicas, onde é mais característico o empenho em busca de orientação doutrinária. De acordo com as informações coletadas nesta pesquisa, os alunos católicos foram os que se disseram menos frequentadores dos cultos religiosos, menos participantes de atividades ligadas à Igreja. Assim, suas crenças religiosas menos doutrinadas devem ter permitido, de certa forma, que eles pudessem estar mais abertos a ideias científicas veiculadas na escola ${ }^{1}$

$\mathrm{Na}$ terceira série, vimos que o ensino científico produziu frutos evidentes no conjunto dos estudantes, embora ainda tenhamos identificado maior permanência de interpretações literais da Bíblia entre os alunos evangélicos. Nestes, foi notório o esforço de contraposição a afirmações que divergissem de suas crenças religiosas. Foram esses os estudantes que, no questionário da pesquisa, afirmaram participar ativamente do dia-a-dia de sua comunidade religiosa - ao contrário do que disseram os alunos católicos -, e fizeram uso frequente de citações ou referências bíblicas como: "O livro de Gênesis da Bíblia disse (...)" ou "Acredito na Bíblia, que diz (...)".

Como os discursos que concentraram o maior percentual de alunos, na terceira série, foram os que declararam que Deus não criou o mundo, que não criou os seres vivos e que não interfere nas causas dos fenômenos da natureza, e deles fizeram parte tanto adeptos quanto não adeptos de crenças religiosas, podemos dizer que esta pesquisa nos permitiu constatar que a presença de crenças religiosas não impede obrigatoriamente a adoção de princípios científicos. No entanto,

\footnotetext{
${ }^{1}$ Estudiosos do catolicismo no Brasil contemporâneo afirmam que "católicos ainda freqüentam relativamente menos sua igreja que os fieis de outras religiões" (Mariz, 2006 p. 54) e que na realidade sociorreligiosa das grandes cidades, é baixa a percentagem dos que se dizem católicos e afirmam "acreditar em Jesus Cristo, Maria e nos ensinamentos da Igreja católica, ou seja, em todas as doutrinas católicas". (Antoniazzi, 2002, p.255).
} 
nesta série, também aumentou a participação de alunos nos discursos que mesclaram ciência a religião. Embora essa mistura resultasse em uma visão que não corresponde ao que defende a ciência, mostrou-nos que esses estudantes trabalharam intelectualmente no sentido de assimilar o ponto de vista científico e assim o fizeram a partir do que já existia em seu universo simbólico, ou cultural, a respeito dessas temáticas, como nos mostram outras pesquisas (COBERN, 1996; CASTRO, AUGUSTO, 2009; COSTA et al, 2011). Provavelmente, a partir de um trabalho docente mais intenso, de modo a melhor distinguir e caracterizar os campos religioso e científico, os alunos pudessem se posicionar de maneira mais clara em relação às explicações científicas e religiosas. Lembre-se que os professores mencionaram o tempo limitado para dar conta de temas considerados relevantes.

É importante ressaltarmos também que, embora a adesão às explicações da ciência aumentasse na terceira série, isso não significou que os estudantes utilizassem sempre argumentos científicos corretos ou fizessem uso mais completo de explicações previstas no programa escolar.

Os discursos que mesclaram explicações científicas e religiosas mostraram compreensão de que a evolução das espécies é um processo gradual. Neles, porém, foram incluídas adaptações explicativas: crenças religiosas e explicações científicas foram articuladas de maneira a que parecessem complementares. A evolução foi aceita, mas seu processo aconteceria sob supervisão divina, como está expresso nos discursos: "Deus só criou um ambiente para que a vida pudesse acontecer e dar frutos (...).É o que penso por causa da religião e da ciência" (Discurso 3, Origem dos seres vivos, 1a série) e "Para mim é um acontecimento divino (...) Deus quis criar, e do resto, a natureza se encarregou, pois eu acredito em evolução das espécies" (Discurso 3, Origem dos seres vivos, 3ạ série).

Observamos que o esforço dos estudantes em compatibilizar crenças religiosas e seus conhecimentos de base científica produziu um discurso lamarquista ${ }^{1}$, ou seja, concebeu-se um direcionamento intencional para a evolução, o que permitiu sua melhor acomodação a crenças religiosas. Ainda assim, nesse discurso, na terceira série, os estudantes mostraram apropriação de termos científicos incluídos no ensino de biologia, ligados ao conceito de evolução - seleção

${ }^{1}$ O termo "discurso lamarkista" refere-se à ideia de determinismo no contexto da teoria evolutiva, defendida pelo naturalista Lamarck (1744-1829). Para ele, o ambiente agiria como pressão determinante de mudanças anatômicas e fisiológicas nos seres vivos. Tais modificações orgânicas tornariam esses seres melhor adaptados ao ambiente (DAWKINS, 1986; MAYR, 1998; GOULD, 2001). 
natural, variabilidade genética e adaptação - ainda que aí faltasse uma compreensão mais clara a seu respeito. De qualquer forma, consideramos relevante assinalar o esforço desses estudantes em acomodar conteúdos escolares à sua base cultural mais ampla, onde se incluem as crenças religiosas. É certo que a interferência docente precisa aí atuar, no sentido de estabelecer distinções necessárias entre o campo da ciência e o da religiosidade para que o estudante se libere do esforço de juntar ciência e religião num mesmo quadro explicativo, distorcendo aspectos da ciência e de suas próprias crenças religiosas.

Os discursos da dúvida revelaram certa inclinação a considerar a origem dos seres vivos como um mistério que escapa a qualquer tentativa de compreensão racional. É bem possível que este posicionamento seja a expressão de uma forma de conflito dos estudantes ante a percepção das dificuldades de juntar explicação científica e religiosa.

Quanto à representação relativa às causas dos fenômenos da natureza, a maioria dos alunos evangélicos, como mostraram os resultados, compartilharam o discurso que afirma que os fenômenos naturais são obras de Deus. Já o discurso que expressa a explicação científica referente às causas dos fenômenos da natureza reuniu, como nenhum outro, a maioria das categorias de crença religiosa e os que a elas não pertenciam. Em outras palavras, nesse tema, católicos, espíritas e também alguns evangélicos, assim como alunos que apenas creem em Deus ou que duvidavam de sua existência e os ateus, todos juntos, apresentaram ideias semelhantes. Todos os alunos, mesmo os que se incluem nas categorias de crenças religiosas, fizeram uso de conhecimentos gerados a partir das ciências da Terra - geologia, paleontologia, geografia, oceanografia, entre outras - para justificarem seus argumentos. Isso nos permitiu concluir que este tema foi o que recebeu, por parte dos estudantes pesquisados, mais clara abordagem científica, se comparado com aqueles referentes à origem do universo e origem e diversidade dos seres vivos.

Foi nessa questão que ateus e religiosos mais se encontraram: afirmaram que as causas dos fenômenos naturais nada têm de misterioso ou divino. Entretanto, os motivos que os levaram a expressar tal convicção foram diversos. Os ateus apareceram sem a referência a Deus, diferentemente dos religiosos que a mostraram.

Consideramos interessante observar a relação entre a ideia de Deus e a interpretação das causas dos fenômenos da natureza dos estudantes pesquisados. O discurso "Os fenômenos da natureza foram criados por Deus" reconhece, na figura de Deus, o poder de criação, controle e consciência sobre os fatos que ocorrem na natureza. Os alunos (maior parte de evangélicos) que compartilharam tal discurso identificaram Deus como juiz dos homens, que os pune à medida que ajam em prejuízo do equilíbrio natural do ambiente. Ao definirem Deus como responsável por todos os fenômenos naturais, catastróficos ou não, esses alunos procuraram evidenciar todo o poder de Deus sobre sua obra. Para eles, Deus tudo pode, construindo ou destruindo o que julgar 
necessário, porque o mundo é criação sua: "Deus também castiga tanto quanto como faz as belezas" (Discurso 1, Fenômenos da natureza, 1a série).

Por outro lado, o Deus que apareceu no discurso "Os fenômenos da natureza não foram criados por Deus" é o pai bondoso e protetor, como o mostra o seguinte texto: "Deus, um ser de amor, bom e que perdoa, não criaria esses fenômenos de propósito (...)" (Discurso 2, Fenômenos da natureza, 1a série). E na terceira série: "Não é nenhum castigo". (Discurso 2, Fenômenos da natureza, 3 a série). Foi na linha dessa percepção que tais estudantes argumentaram a favor das causas naturais dos fenômenos da natureza.

Finalizando a discussão dos resultados, é possível dizer que no conjunto dos estudantes investigados, observamos um crescimento significativo do emprego de termos e expressões científicas nos discursos da terceira série. Assim, podemos dizer que, embora a ancoragem religiosa tenha permanecido entre parte dos estudantes, a ancoragem científica apresentou notável avanço na série final do ensino médio e esse resultado mostra os efeitos das ações educativas de uma escola que conta não só com professores bem formados como com razoável estrutura de apoio e material pedagógico.

\section{Conclusão}

Os resultados da pesquisa nos mostraram que, em relação a dois dos temas investigados origem do universo e origem da diversidade dos seres vivos - houve claras referências, tanto às explicações religiosas, quanto às científicas, nos discursos expressos pelos estudantes dos dois grupos investigados. Entretanto, a adesão ao discurso de base científica ampliou-se na última série, ou seja, a maior parte dos estudantes da terceira série ou renunciou a algumas crenças religiosas (principalmente às relacionadas à ideia de um Deus criador, cuja ação prescindiria de explicações da ciência) ou mostrou esforços para compatibilizar a explicação da criação divina, exposta na Bíblia, com a da evolução, defendida pela ciência. Assim, fez-se notório, nos dois grupos, o esforço de estudantes para harmonizar, a partir de sua base cultural, explicações religiosas e científicas no que se refere às questões da origem do universo e da vida.

Em relação ao terceiro tema - causas dos fenômenos naturais -, observamos uma particularidade: os resultados foram praticamente idênticos nos dois grupos. Em ambos, a grande maioria dos alunos, nas suas diversas categorias por nós levantadas, mostrou-se mais receptiva às explicações científicas, o que não aconteceu, pelo menos em tal proporção, no que se refere aos dois temas antes mencionados. Consideramos que essa diferença pode ligar-se ao fato de estar a origem do universo e da vida fortemente associada, na visão dos que creem, à ação de um Deus criador e poderoso. Esses temas, portanto, aparecem como mais ligados aos fundamentos das crenças religiosas. Tal suposição se reforça na medida em que verificamos, nos diferentes 
discursos dos estudantes investigados, que tal associação veio frequentemente justificada por citações bíblicas. Já os "terremotos", "tempestades", "eclipses" e outros fenômenos naturais são percebidos como posteriores àqueles originários e mais grandiosos, associados à ação divina. Os estudantes apreenderam esses conteúdos, mais facilmente, como fatos cuja explicação caberia à ciência. Os resultados da pesquisa indicam, dessa forma, que houve influência das crenças religiosas na aprendizagem dos conteúdos escolares, de base científica, oferecidos aos estudantes investigados. Tal influência, por vezes, provocou rejeição às explicações da ciência, principalmente por parte dos alunos evangélicos, já que constatamos, entre os católicos, uma tendência de maior aceitação dessas explicações.

Entretanto, não podemos afirmar que rejeições às explicações científicas possam ser atribuídas exclusivamente às influências de crenças religiosas dos estudantes porque também verificamos que professores disseram ser limitado o tempo dedicado aos temas investigados, o que nos permite considerar a possibilidade de haver falhas no ensino de tais temas. Dentro desse quadro, as crenças religiosas tenderiam a aparecer como mais relevantes para parte dos estudantes porque não só foram oferecidas a eles em extenso espaço de tempo (os estudantes frequentam igrejas e têm familiares religiosos) como estão enraizadas socialmente em seus espaços familiares e de vida cotidiana. Nesse contexto, entendemos por que, em diferentes momentos da pesquisa, ouvimos ou lemos nas respostas aos questionários a declaração "Por que trocar a religião pela ciência?". Essa frase vem associada à constatação de estudantes de que a ciência muda muito e a religião, tendo a referência da Bíblia, não muda. Note-se que essa observação dos estudantes, não rara nos contextos escolares, mostra a demanda da abordagem histórica e sociológica da produção do conhecimento científico no ensino de ciências, como destacam documentos oficiais que orientam o ensino básico: “(...) O aprendizado de Biologia deve permitir (...) a compreensão de que a ciência não tem respostas definitivas para tudo, sendo uma de suas características a possibilidade de ser questionada e de se transformar". (PCN's, Brasil, 1999, p.14).

Nossas conclusões nos alertam a pensar sobre a relevância dos aspectos culturais mais amplos associados aos temas investigados. Essa relevância não se deve apenas ao fato de que crenças religiosas influenciam a aprendizagem desses temas. Ela se deve também à importância que os estudantes atribuem a esses temas em suas vidas, ligados que estão a vivências religiosas, de alto valor para parte considerável dos alunos conforme foi possível ver nos seus esforços de compatibilizar explicações religiosas e científicas. Esse fato precisa necessariamente ser levado em conta ao tratar-se desses temas em sala de aula. Nesse contexto, é urgente a necessidade de refletirmos sobre qual seria o espaço de tempo mais adequado ao ensino de ciências previsto para o ensino médio, pois nos parece notório que o tempo disponível pode ser decisivo para os processos de compreensão e assimilação mais corretas por parte dos alunos. 
Finalmente, não se pode relevar o que pesquisas, conforme citadas no inicio desse artigo, já apontaram: o proselitismo religioso que dissemina o criacionismo tem ampliado suas ações em diferentes grupos. O domínio científico dos conteúdos da Teoria da Evolução pelos professores de Biologia é tão importante quanto a familiaridade com as informações e discussões relativas à história e sociologia das ciências. Esse preparo profissional tanto esclarece o espaço da ciência e das crenças religiosas nas culturas humanas quanto qualifica o papel docente nas salas de aula. 0 professor precisa estar em condições de dialogar com os estudantes de forma aberta no sentido de não ignorar suas características culturais, o que condiz com a formação científica conforme prevista para o ensino médio. Este preparo profissional, no entanto, torna cada vez mais clara a necessidade de recompor, nos meios acadêmicos das ciências naturais, a ideia da natureza do conhecimento científico e localizá-lo no tempo presente e no passado. Para isso, não só em relação aos cursos de formação de professores de ciência e biologia (DELIZOICOV et al., 2002), mas também nos que formam os próprios cientistas, é mais que necessário, urgente, que disciplinas ligadas à história da ciência, sociologia do conhecimento científico e filosofia da ciência sejam introduzidas ao currículo desses futuros profissionais.

\section{Referências bibliográficas}

ABRANTES, P.; ALMEIDA, F. P. L. Criacionismo e darwinismo confrontam-se nos tribunais da razão e do direito. Episteme, v. 11, n. 24: 357-402. 2006.

ALMEIDA, D. F. Concepções de Alunos do ensino médio sobre a origem das espécies. Ciência \& Educação, 18, 1. Bauru, 2012.

ANTONIAZZI, A. Perspectivas pastorais a partir da pesquisa in Desafios do Catolicismo na Cidade: pesquisa em regiões metropolitanas brasileiras/ CERIS -São Paulo: Paulus, 2002. p.252-267

BIZZO, N. M. V. From Down House landlord to Brazilian highschool-students - what has happened to evolutionary knowledge on the way? Journal of Research in Science Teaching, v. 31, p. 537556, 1994.

BLALOCK, H. Social statistics. New York: McGraw-Hill, 1979.

CANEN, A. MOREIRA, A. F. B. (Orgs.). Ênfases e Omissões no Currículo. Campinas: Papirus, 2001.

CASTRO, N. B.L.; AUGUSTO, T. G. S. Análise dos trabalhos sobre o ensino de evolução biológica publicados nos anais do VI ENPEC. Anais do VII ENPEC. Florianópolis, 2009.

CHASSOT. A. Inserindo a História da Ciência no Fazer Educação. In: CHASSOT, A; OLIVEIRA, R. J. (org.) Ciência, Ética e Cultura na Educação. São Leopoldo: Unisinos, 1998.

134 DOI: Em andamento.

R. Bras. de Ensino de C\&T 
COBERN, W. Worldview theory and conceptual change in science education. Science Education, 80, 5, 579-610, 1996.

CHIZZOTTI, A. ; PONCE, J.B. O currículo e os sistemas de ensino no Brasil. Currículo sem Fronteiras, v.12,n.3,p.25-36,Set/Dez.2012

COSTA, L.; LEANDRO O.; MELO, P. L. C.; TEIXEIRA, F. M. Reflexões acerca das diferentes visões de alunos do ensino médio sobre a origem da diversidade biológica. Revista Ciência \& Educação, 17, 1. Bauru, 2011.

DAWKINS, Richard. O Relojoeiro Cego. Lisboa/Portugal: Edições 70, 1986.

DELIZOICOV, D.; ANGOTTI, J. A .; PERNAMBUCO, M. M. Ensino de Ciências: Fundamentos e Métodos. São Paulo: Cortez, 2002.

GEERTZ, C. A Interpretação das Culturas. Rio de Janeiro: LTC -Livros Técnicos e Científicos Editora S. A., 1989.

GIL-PÉREZ, D.; VILCHES, A. e EDWARDS, M. Las concepciones de los professores de ciências brasileños sobre la situación del mundo. Investigações em Ensino em Ciência, 5, 3, 213-236. 2000.

GOULD, S. J. Lance de Dados - A ideia de Evolução de Platão a Darwin. Rio de Janeiro: Record, 2001.

GRIMOULT, C. Créationnismes: Mirages et Contrevérités. CNRS Éditions, Paris, 2012.

LEFÈVRE, F. e LEFÈVRE, A. O Discurso do Sujeito Coletivo: um novo enfoque em pesquisa qualitativa (desdobramentos). Caxias do Sul: EDUSC. 2003.

LOPES, A. R. C. Currículo, Conhecimento e Cultura: Construindo Tessituras Plurais. In: CHASSOT, A; OLIVEIRA, R. J. (org.) Ciência, Ética e Cultura na Educação. São Leopoldo/ RS : Unisinos, 1998.

MARIZ, C. L. Catolicismo no Brasil contemporâneo: reavivamento e diversidade In : As Religiões no Brasil: Continuidade e rupturas. Petrópolis,RJ : Editora Vozes Ltda. 2006, p.53-68.

MAYR, E. O Desenvolvimento do Pensamento Biológico: Diversidade, Evolução e Herança. Brasília, DF: Editora Universidade de Brasília, 1998.

MELLO, A. C. Evolução biológica: concepções de alunos e reflexões didáticas. Dissertação de Mestrado/PUC. Porto Alegre, 2008.

MORIN, Edgar. A Religação dos Saberes - O desafio do Século XXI. Rio de Janeiro: Bertrand Brasil, 2002

MOSCOVICl, S. Representações sociais: investigações em psicologia social. Petrópolis: Editora Vozes. 2003.

R. B. E. C. T., vol 8, núm. 1, jan-abr.2015 ISSN - 1982-873X

DOI: Em andamento. 
OLIVEIRA, R. J. A Escola e o Ensino de Ciências. São Leopoldo: Ed. UNISINOS, 2000.

REISS, M. (2009). Imagining the World: the Significance of Religion Worlviews for Science Education. Science \& Education 18, 6-7, 783-796. 2009.

SECRETARIA DE EDUCAÇÃO MÉDIA E TECNOLÓGICA. Parâmetros Curriculares Nacionais: Ensino Médio. Vol. 3, Brasília/ DF: MEC, 1999.

SECRETARIA DE EDUCAÇÃO FUndAMENTAL. Parâmetros Curriculares Nacionais: Ciências Naturais. Ensino de quinta a oitava séries. Brasília/ DF: MEC, 1998.

SEPÚLVEDA, C. Movimento criacionista: um risco à formação científica e cultural dos alunos da rede pública carioca. Boletim da SBEnBio, 1, 4-9. 2004.

SOUZA, R. F. de; CARVALHO, M. de; MATSUO, T. e ZAIA, D. A. M. Evolucionismo x Criacionismo: aceitação e rejeição no século 21. Ciência Hoje, 43, 36-41. 2009

TIDON,R; LEWONTIN, R. C. Teaching evolutionary biology. Genetics and Molecular Biology, 2004. TIDON, R.; VIEIRA, E. O ensino de evolução biológica: um desafio para o século XXI. Revista Com Ciência, 107. Campinas, 2009.

Eliane Dias Trigo. Mestre em Tecnologia Educacional para a Saúde-NUTES/Universidade Federal do Rio de Janeiro (UFRJ). Graduada em Biologia (UFRJ). Professora de Biologia do Colégio Pedro II/ Rio de Janeiro. E-mail edtrigo@gmail.com

Eliane Brígida Morais Falcão. Doutora em Engenharia de Produção- COPPE/Universidade Federal do Rio de Janeiro (UFRJ), tem pós-doutorado na Universidade de Cambridge (Reino Unido). Professora do Programa de Pós-graduação em "Educação em Ciências e Saúde" do Núcleo de Tecnologia Educacional para a Saúde (NUTES)/UFRJ. Coordena o Laboratório de Estudos da Ciência (NUTES/UFRJ). É pesquisadora do Observatório da Laicidade da Educação (OLÉ). Atua nos temas: 1.Ciência e religião com ênfase na análise da presença das crenças religiosas entre cientistas e estudantes em formação científica. 2.0 ensino da origem da vida e evolução das espécies. 3."Ensino da morte" na formação universitária e no ensino médio.

E-mail elianebrigida@uol.com.br 